\title{
Search for consanguinity within and among families of patients with trichothiodystrophy associated with xeroderma pigmentosum
}

Fiorella Nuzzo, Gianna Zei, Miria Stefanini, Rita Colognola, Augusta Silvana Santachiara, Paola Lagomarsini, Stefano Marinoni, Laura Salvaneschi

\begin{abstract}
The association of two rare hereditary disorders, trichothiodystrophy (TTD) and xeroderma pigmentosum (XP), was found in four patients from three families, apparently unrelated but living in the same geographical area. In order to test the hypothesis of a common ancestor, consanguinity within and among the families was checked using three different approaches: reconstruction of genealogical trees, typing of blood markers, and surname analysis.

The results of the three types of analyses strengthen the hypothesis that, in at least two out of the three families, the genetic defect determining the TTD/XP phenotype is identical by descent, as a consequence of remote inbreeding. This implies that if two mutations are responsible for the two diseases they are at linked loci or affect the same gene.
\end{abstract}

The hereditary disorders xeroderma pigmentosum (XP) and trichothiodystrophy (TTD) have both been found to be present in patients showing clinical and cellular photosensitivity, typical of XP, in addition to clinical traits of TTD (brittle hair with reduced sulphur content, ichthyosis, physical and mental retardation). ${ }^{1}$

At present, 19 photosensitive TTD patients have been reported; DNA repair studies have been performed in cells from 10 patients and

Istituto di Genetica Biochimica ed Evoluzionistica, CNR, Via Abbiategrasso 207, 27100 Pavia, Italy.

F Nuzzo, G Zei, M Stefanini, R Colognola, P Lagomarsini

Dipartimento di Genetica e Microbiologia 'A BuzzatiTraverso', Università di Pavia, Italy.

A S Santachiara

Istituto per l'Infanzia, Trieste, Italy.

S Marinoni

Centro Trasfusionale AVIS, Pavia, Italy.

L Salvaneschi

Correspondence to Dr Nuzzo.

Received for publication 14 December 1988

Revised version accepted for publication 27 June 1989. complementation analysis showed the presence of the XP group D (XP-D) mutation in all of them. ${ }^{2}$

XP and TTD are both autosomal recessive disorders resulting from single gene defects. Homozygote frequency is very low: XP occurs in 1 out of 250000 subjects, the XP-D patients comprising about $10 \%$ of all the XP cases investigated. ${ }^{4}$ The incidence of TTD is unknown; a total of 81 patients (with and without photosensitivity) from 51 families has been reported since $1963 .^{2}$ Thus, the presence of the homozygous conditions for both mutations is a highly improbable event and alternative explanations should be considered for the occurrence of the complex XP-D/ TTD phenotype.

The four patients described by Stefanini et al, ${ }^{1}$ belonging to three families, apparently unrelated but living in the same geographical area, offer the opportunity to investigate some genetic aspects, in particular the identity of the defect.

We checked consanguinity within and among the three families using different approaches, namely the reconstruction of genealogical trees, the study of blood genetic markers, and the analysis of surnames.

\section{Materials and methods}

The families studied (families 1, 2, and 3) originated from, and currently live in, small towns no more than $100 \mathrm{~km}$ apart, located in an area of about $1600 \mathrm{~km}^{2}$ in the plain behind the Alps in north-east Italy (Veneto and Friuli-Venezia Giulia regions).

Data for the construction of pedigrees and surnames were obtained by direct interview and from registers of births, marriages, and deaths and area statistics. Data on consanguinity in these regions were obtained from the list of consanguineous marriages available for the period 1911 to 1964 (Moroni and Zei, unpublished data).

Blood samples were obtained from three patients affected by XP-D and TTD (one from family 1, two from family 2), from their parents, from the parents of a dead affected child (from family 3), and from relatives in the three families. The subjects examined, that is, 11 from family 1,12 from family 2 , and eight from family 3 , are shown in fig 1 . 


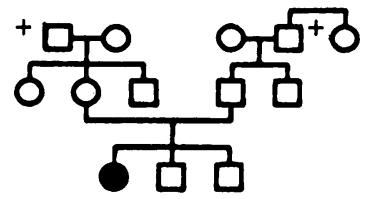

Family 1

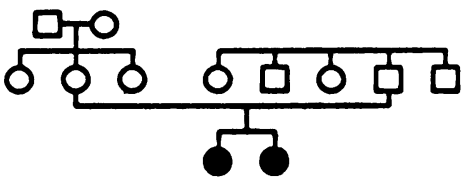

Family 2

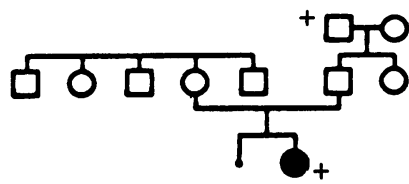

Family 3

Figure 1 Partial pedigrees of the three families including the subjects examined. $\bigcirc=$ affected children (for clinical and cellular studies see Stefanini et al $\left.{ }^{1}\right) ;+=$ not examined, dead.

The following markers, with chromosome location indicated in brackets, were analysed: blood groups ABO (9), Duffy a b (1), Kidd a b (2), Kell K k (?), Lewis a b (19), MNSs (4), P1 (22), Rhesus CcCwDEe (1); red cell enzymes ACP (2), ADA (20), DIAl (22), ESD (13), GLO-1 (6), GPI (19), GPT (8), PEP A (18), PEP B (12), PEP C (1), 6PGD (1), PGM1 subtype (1), PGM2 (4); serum proteins C3 (19), GC subtype (4), Hp (16), Tf (3), Pi (14).

\section{Results}

PEDIGREES

The construction of pedigrees was performed using data from the parish registers and birth and marriage certificates; however, the difficulty of exploring the oldest records meant that we could not trace the three pedigrees through the same number of generations.

For families 1 and 3 the pedigrees were almost completely constructed for four generations only. One

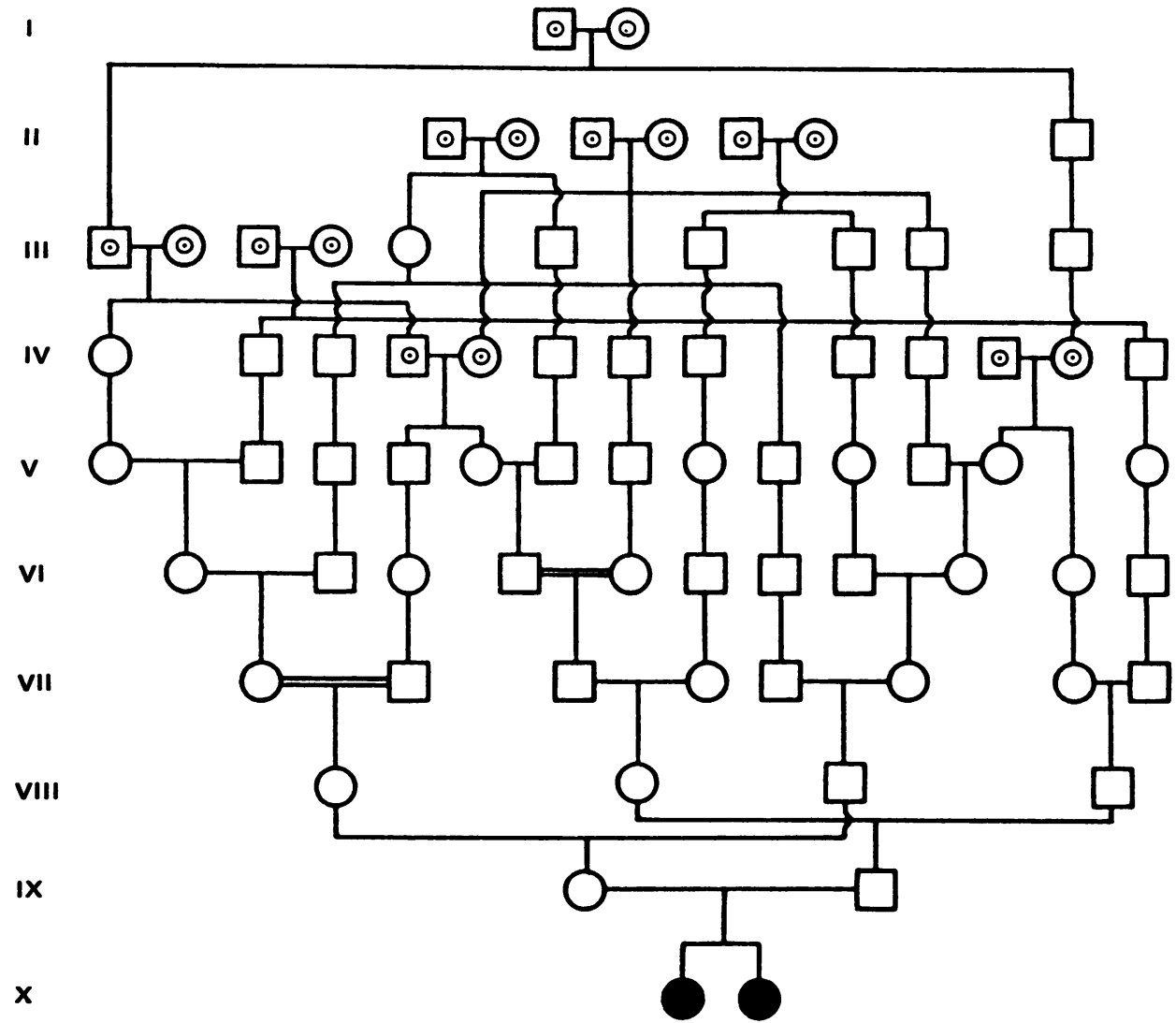

Figure 2 Partial pedigree of family 2. Circles within symbols indicate the common ancestors. 
consanguineous marriage was found in the maternal branch of family 3 ; the information available did not indicate consanguinity in the parents of affected children. More extensive data were obtained for family 2, allowing the construction of the pedigree through nine generations. Sixteen common ancestors, corresponding to eight married couples, were identified in generations I to IV, spanning from 1700 to 1820 approximately (fig 2 ). The inbreeding coefficient of the affected children $\left(F=\Sigma(1 / 2)^{n+1}\right)$ was estimated on the basis of 26 separate and mutually exclusive paths of $\mathbf{n}$ generations connecting the parents through the common ancestors. The $F$ value obtained $\left(\mathrm{F}=0.4302 \times 10^{-2}\right)$ corresponds to that of a third cousin progeny $\left(\mathrm{F}=0.3906 \times 10^{-2}\right)$.

\section{BLOOD MARKERS}

Twenty-seven independent markers, localised on 15 autosomes, were analysed on blood samples obtained from the patients and the obligate and possible carriers included in the partial pedigrees shown in fig 1.

No variant phenotypes were observed for the following red cell enzymes: DIA, GPI, PEP A, PEP $B$, PEP C, and PGM2, which are usually monomorphic markers. Only the most common phenotype was found for $\mathrm{AK}$ and 6PGD in all the subjects tested, as well as for ESD and Tf in family 1 , for C3 and P1 in family 2, and for ADA in family 1 . The remaining markers (ACP, GLO-1, GPT, PGM1, GC, Hp, ABO, Duffy, Kidd, Kell, Lewis, MNSs, Pi, Rhesus) were present with different alleles in the three families. In order to check the hypothesis of consanguinity, we looked for the presence of rare genetic markers in the three families, having chosen as 'rare' the alleles with a frequency in the population lower than $12 \%$. To avoid redundancy of information, data obtained from subjects tested in the grandparental generation were considered. We actually examined only two subjects in family 1 , two in family 2, and one in family 3 . However, for some of the missing grandparents it was possible to infer the genotype of one or both alleles from those of their offspring.

None of the rare alleles was present in all the three families, whereas four were present in families 1 and 2 , two in families 1 and 3 , and one in families 2 and 3. To test the hypothesis of independence (absence of consanguinity) between pairs of families the probability $\mathrm{p}$ for each rare allele $a$ with frequency q to be present by chance, once or more, in two families, $i$ and $\mathrm{j}$, was computed as:

$$
\mathrm{p}=\left(1-\mathrm{P}^{\mathrm{n}_{\mathrm{i}}}\right)\left(1-\mathrm{P}^{\mathrm{n}_{\mathrm{i}}}\right)
$$

where $\mathrm{P}$ was the frequency of the alleles other than $a$ and $n_{i}, n_{j}$ were the total number of alleles tested in
Table 1 'Rare' alleles present in the grandparental generation of the three families.

\begin{tabular}{|c|c|c|c|c|c|c|}
\hline \multirow[b]{2}{*}{ System } & \multirow[b]{2}{*}{ Allele } & \multirow{2}{*}{$\begin{array}{l}\text { Frequency } \\
\text { in the } \\
\text { population* }\end{array}$} & \multicolumn{3}{|c|}{$\begin{array}{c}\text { Presence of the rare } \\
\text { allelet }\end{array}$} & \multirow[b]{2}{*}{$\mathrm{p} \ddagger$} \\
\hline & & & 1 & $\underset{2}{\text { Family }}$ & 3 & \\
\hline $\begin{array}{l}\text { ABO } \\
\text { MNS } \\
\text { Kell } \\
\text { ACP } \\
\text { PGM1 } \\
\text { Pi } \\
\text { ADA }\end{array}$ & $\begin{array}{l}\text { B } \\
\text { NS } \\
\mathrm{K} \\
\mathrm{C} \\
\mathbf{1}^{\mathbf{F}} \\
\mathbf{M}_{3} \\
2\end{array}$ & $\begin{array}{l}0.0683 \\
0.0501 \\
0.0326 \\
0.0697 \\
0.1130 \\
0.0450 \\
0.0891\end{array}$ & $\begin{array}{l}+(7) \\
+(7) \\
+(7) \\
+(6) \\
+(6) \\
+(7) \\
-\end{array}$ & $\begin{array}{l}+(7) \\
+(8) \\
+(7) \\
+(8) \\
- \\
+(7)\end{array}$ & $\begin{array}{l}\overline{-} \\
\overline{-} \\
+(6) \\
+(6) \\
+(6)\end{array}$ & $\begin{array}{l}0.15253 \\
0.10187 \\
0.04287 \\
0.13561 \\
0.23150 \\
0.05893 \\
0.20565\end{array}$ \\
\hline
\end{tabular}

${ }^{*}$ The allele frequencies are those reported for regions of northern Italy: (ABO, MNS), ${ }^{6}$ (Kell, ACP, ADA), ${ }^{7}$ (PGMl) ${ }^{8}$ (Pi). ${ }^{9}$ In brackets is the total number of the alleles ascertained. $\ddagger$ See text.

family $i$ and in family $i$ respectively. Among the $p$ values estimated for the seven alleles (table 1), only that concerning the $\mathrm{K}$ allele present in families 1 and 2 was lower than 0.05 , the others varying from 0.059 to 0.231 . Using the mean $\mathrm{p}$ value $(0.13271)$, the probability of the simultaneous presence, by chance, in the same two families of a given number of rare independent alleles out of the seven was estimated. A probability of 0.0078 for families 1 and 2 to have in common, by chance, four (or more) alleles was obtained. This result supports the hypothesis of consanguinity between the two families. The estimated probability for the simultaneous presence of two alleles only $(p=0.235)$, as observed in families 1 and 3, was not sufficient to reject the hypothesis of independence.

When a rare allele was present twice in a family, in the paternal and in the maternal line, we carried out the same statistical analysis testing the hypothesis of independence between paternal and maternal grandparents. The results reported in table 2 confirm the consanguinity within family 2 , since a low probability value $(p \simeq 0.05)$ for the rare alleles of the Kell and ACP systems was obtained. For the rare alleles of the PGM1 and ADA systems, in families 1 and 3 respectively, this probability was not significant and did not exceed the 0.1 level.

Table 2 'Rare' alleles present in maternal and paternal lines of the three families.

\begin{tabular}{llccc}
\hline Family & System & $\begin{array}{c}\text { Paternal } \\
\text { line* }\end{array}$ & $\begin{array}{c}\text { Maternal } \\
\text { line* }\end{array}$ & p \\
\hline 1 & PGM1 & $+(2)$ & $+(4)$ & 0.08124 \\
2 & Kell & $+(3)$ & $+(4)$ & 0.01175 \\
& ACP & $+(4)$ & $+(4)$ & 0.05449 \\
3 & ADA & $+(3)$ & $+(3)$ & 0.05963
\end{tabular}

*In brackets is the total number of alleles ascertained. 


\section{SURNAMES}

The method of surnames, introduced by Crow and Mange $^{10}$ to estimate the inbreeding coefficient of a population, has been applied in different studies on genetic population structure. ${ }^{11} 12 \mathrm{We}$ analysed surnames searching for isonymy that could indicate ancestral relationships within and among the families. In the course of pedigree construction, the surnames of 396 subjects were obtained for the three families. Out of 194 different surnames expected, after taking into account the repetition of the paternal surname, we found 117 different surnames. The difference is because the same surname was present more than once in each pedigree. This can be considered as an indication of consanguinity. The most conspicuous difference was found in family 2 (26 surnames observed $v 83$ expected); this actually corresponds to the high degree of consanguinity shown by the reconstructed pedigree (fig 2).

The analysis of surnames in each pedigree showed that the paternal and maternal lines of the tree in families 1,2 , and 3 share $1 / 51,7 / 26$, and $0 / 40$ surnames, respectively. This finding also confirms the multiple consanguinity in family 2 .

None of the 117 total surnames was present in more than one family. To account for errors in interpretation of writing and in surname transcription on birth and marriage registers occurring over the years, an analysis of spelling of similar surnames was carried out, using the results of a historical-linguistic study of the surnames in the region. ${ }^{13}$ This allowed us to consider some similar surnames which had originally been identical; seven pairs of such surnames were identified, one shared by families 1 and 2 , three by families 1 and 3, and three by families 2 and 3 .

\section{Discussion}

The occurrence of the association of two rare hereditary disorders in three apparently unrelated families living in the same geographical area led us to search for consanguinity using different approaches. The results of our investigations indicate a genetic relationship either within the families or between pairs of families.

The presence of multiple, remote consanguinity is directly shown in family 2 by the reconstruction of the pedigree, from which it was possible to estimate an inbreeding coefficient corresponding to that of a third cousin progeny.

Consanguinity in family 2 is confirmed by the occurrence of several rare blood markers in the maternal and paternal grandparents, as well as by the presence of surnames shared by the paternal and maternal line. A genetic relationship within the other two families, whose pedigrees were incomplete, is suggested by blood marker analysis.

The incompleteness of the pedigrees does not allow any conclusion about the relationship between all the three families. However, a relationship between families 1 and 2 is indicated by the presence of the same four rare alleles; a relationship between families 1 and 3, 2 and 3, and possibly also 1 and 2 is suggested by the presence of similar surnames that could originally have been identical. Taking into account the caution required for the use of surnames as genetic markers, this adds further evidence in favour of consanguinity, although based on the same few data as available for the pedigrees.

In conclusion, the results of the three types of analyses strengthen the hypothesis that the affected children are carriers of a genetic defect identical by descent, as a consequence of remote, multiple inbreeding. This implies that if two mutations are responsible for XP-D and TTD, they have been transmitted together throughout at least nine generations to the heterozygous carriers and then to the affected children. Therefore the two loci must be closely linked on the same chromosome. Obviously a deletion involving the relevant gene(s) could be the basis of the abnormal phenotype. However cytogenetic analysis carried out in the Italian patients and their parents did not show any chromosome anomaly. ${ }^{14}$

The presence of a common ancestor, while strongly suggesting one of the possibilities mentioned before, does not exclude other genetic situations. In the evaluation of different hypotheses, it is worth noticing that the XP-D/TTD association is not limited to the Italian cases, being also present, as recently reported, in unrelated patients from different countries. ${ }^{2}{ }^{3}$ In fact, the genetic defect leading to the XP-D/TTD association could consist in the heterozygous condition for compound genes or in the homozygous condition for more than two defective genes, each involved in one of the multiple steps of DNA repair process, according to the corecessive model of inheritance proposed by Lambert and Lambert. ${ }^{15}$

Further investigations, and in particular molecular analysis and isolation of specific probes, are needed to elucidate the genetic basis of the XP-D/TTD phenotype.

The authors wish to thank Professor L De Carli and Dr C Matessi for helpful suggestions and criticism and Mrs D Tavarnè for typing the manuscript. This work was partially supported by grants from the Commission European Communities (contract BI6158-I) and Associazione Italiana per la Ricerca sul Cancro. P Lagomarsini was supported by a fellowship from the AIRC.

1 Stefanini M, Lagomarsini P, Arlett CF, et al. Xeroderma pigmentosum (complementation group D) mutation is present in patients affected by trichothiodystrophy with photosensitivity. Hum Genet 1986;74:107-12. 
2 Stetanini M, Lagomarsini P, Nuzzo F. Genetic analysis in trichothiodystrophy repair deficient cells confirms the occurrence of xeroderma pigmentosum group D mutation in unrelated patients. In: Lambert $\mathrm{MW}$, ed. DNA repair mechanisms and their biological implications in mammalian cells. New York: Plenum Press, 1989.

3 Lehmann AR, Arlett CF, Broughton BC, et al. Trichothiodystrophy, a human DNA repair disorder with heterogeneity in the cellular response to ultraviolet light. Cancer Res 1988;48:6090-6.

4 Cleaver JE. Xeroderma pigmentosum. In: Stanbury JB, Wyngaarden JB, Fredrickson DS, Goldstein JL, Brown MS, eds. The metabolic basis of inherited disease. New York: McGraw-Hill, 1983:1227-48.

5 Jung EG. Xeroderma pigmentosum. Int $\mathcal{F}$ Dermatol 1986;25:629 33 .

6 Mourant AE, Kopec AC, Domaniewska-Sobczak K. The distribution of the human blood groups and other polymorphisms. London: Oxford University Press, 1976.

7 Piazza A, Olivetti E, Carbonara $\mathrm{AO}$, et al. La distribuzione di alcuni polimorfismi genetici in Italia. Milano: Il Ponte, 1982.

8 Ranzani GN, Bordicka R, Antonini G, et al. Electrophoretic subtyping of phosphoglucomutase locus 1 (PGM $)$ polymorphism in the Italian and Czechoslovakian populations. Hum Hered 1985;35:273-8.

9 Pascali VL, Massa G. Alpha-1-antitrypsin in Italy: absence of a North to South cline of frequencies. $\mathcal{F}$ Hum Evolution 1984;13:335-8.

10 Crow JF, Mange A. Measurement of inbreeding from the frequency of marriages between persons of the same surname. Eugen Ouart 1965;12:199-203.

11 Zei G, Piazza A, Moroni A, et al. Surnames in Sardinia III. The spatial distribution of surnames for testing neutrality of genes. Ann Hum Genet 1986;50:169-80.

12 Proceedings of the conference on Surnames as markers of inbreeding and migration. Arranged by Gottlieb BK. Hum Biol 1983;55:209-408.

13 De Felice M. Dizionario dei cognomi italiani. Milano: Arnoldo Mondadori, 1978.

14 Nuzzo F, Stefanini M, Rocchi M, et al. Chromosome and blood markers study in families of patients affected by xeroderma pigmentosum and trichothiodystrophy. Mutat Res 1988;208:159-61.

15 Lambert WC, Lambert MW. Co-recessive inheritance: a model for DNA repair, genetic disease and carcinogenesis. Mutat Res 1985;145:227-34. 